bear the name of an explorer. Many rivers have great variations in level, but that of 90 feet on portions of the Salwin is probably unsurpassed. A unique feature appears in the St. John River of New Brunswick, where the condition of its lower sunken valley causes its waters to extend up the parallel valleys of tributaries in a system of navigable lakes or bays that mildly suggest Norwegian fiords. It remains, however, for the little Zeta River of Montenegro to perform the strangest feat of any stream, a truly novel performance by which the waters suddenly dive underground, pass directly beneath a mountain 1,000 feet high and emerge again to daylight a few miles beyond.

Any statement as to which world-famous river is most interesting would undoubtedly be promptly challenged. Advocates would appear for the Mississippi, Nile, Rhine, Danube, Euphrates and various other streams. With due caution, however, we venture the suggestion that the least interesting very great river, topographically and historically, is the mighty Lena, meandering about the bleak plains of Northern Siberia. The greatest geographical discoveries of the future, so far as they relate to rivers, may reasonably be expected from two quarters of the globe, the first including the northerly and southerly portions of the Congo basin, the second embracing the mountainous region between the Eastern Himalayas and the valley of the Yang-tse-Kiang, where considerable portions of three great streams, the Brahmapootra, Salwin and Mekong yet remain insufficiently explored.

\title{
Equilibrium and Equilibrium Organs in Lower Animals*
}

\author{
The Special Sense of "Up and Down"
}

By Dr. W. Baunacke

IN addition to the organs of sight, hearing, taste, smell, and touch, all vertebrate animals, including man, possess more complex tactile organs which control the position and direct the movement of the body. The labyrinth of the ear belongs to this class.

Similar organs, of ten of more primitive structure, are found in all classes of multicellular animals, but not in all species. With few exceptions the operation of these equilibrium organs is dependent upon gravitation, and they give their possessors a sense of the vertical as a fixed direction and of the position of the body with respect to that line of reference. The manner in which this task is performed depends upon the structure of the organ, which varies greatly in different classes, genera, even species of invertebrates, in which the organs do not, as in vertebrates, represent successive stages in a common evolutionary series, but are rather convergence structures, which lack a common morphological origin, although they perform similar functions.

Yet there is a fundamental type, the statocyst (Fig. 1), a globular vesicle filled with a watery fluid, called endolymph, and containing one or more unattached solid

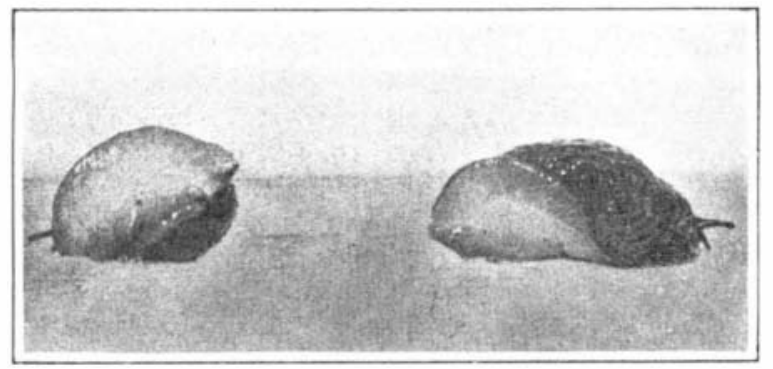

Fig. 2.-Inverted snails righting themselves

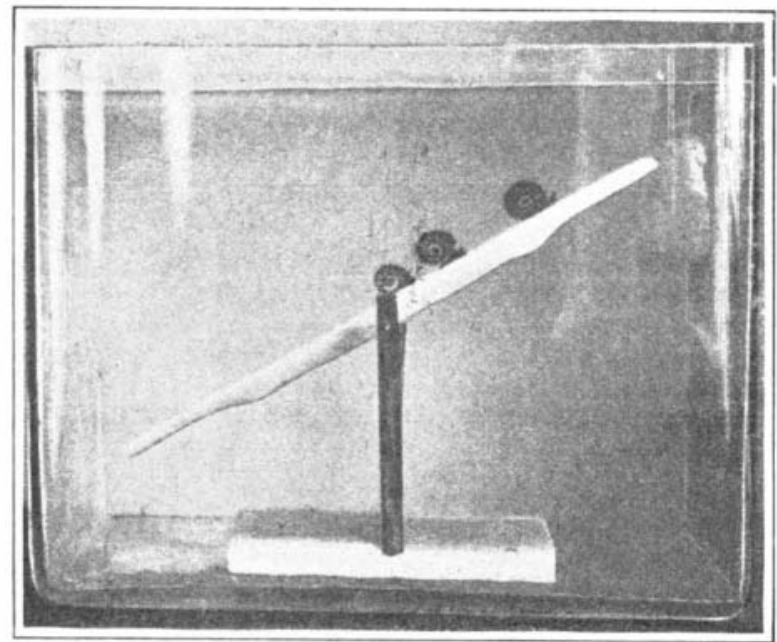

Fig. 3.-Land snails ascending a see-saw in water.

particles. These particles, or statoliths, are either calcareous concretions formed inside the body, or grains of sand or other foreign matter of external origin. As the body moves, the statolith continually seeks the lowest part of the cavity, and in so doing impresses upon the nerve cells of the wall of the statocyst stimuli which are transmitted to the central nervous system and evoke motor impulses corresponding to the actual position of motor im

the body.
These organs were regarded as organs of hearing, and were called otocysts and otoliths, until it was proved by ingenious experiments that the reactions of these animals to sounds are reflex movements of flight, caused by feeling, not hearing the vibration of the surrounding medium. Subsequently it was shown that sense organs of this type exert an immediate effect upon muscular tension, and that exert an immediate effect upon muscular tension, and that
the movement of the statolith with each change of position produces, in the nerve cells of the statocyst, varying contact stimuli, which cause the legs, wings or fins to move so as to maintain or restore the equilibrium of the body. All organs of this character, therefore, are classed as equilibrium organs.

The sieve-like perforations found in the water scorpion (Nepa cinerea) and some other aquatic insects, which

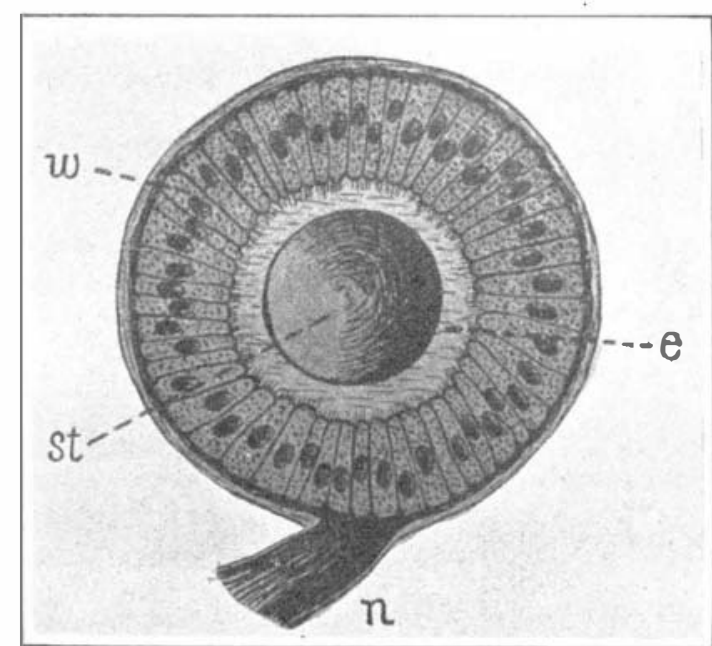

Fig. 1. -Statocyst of fresh-water mussel. t, statolyth ; $v$, nerve-cells; 6 , endolymph ; $n$, nerve.

formerly were assumed to be respiratory organs, have been proved by experiment and anatomical research to be sense organs, which enable the animal to direct its course when crawling under water. This was the first discovery, in insects, of organs of equilibrium such as had been observed in representatives of all other classes of multicellular animals. These organs of the water scorpion, however, differ greatly from the typical static or equiliorium organ, the statocyst. In the water scorpion the stimulus is determined by the movement of a lighter body, air, through a heavier medium, water. Furthermore, the function of the insect organ is not to maintain equilibrium, but to cause, in definite external conditions, definite movements of the whole body, which are of great biological importance. These movements are negatively geotactic, i. e., they are directed away from the earth's center.

The question arises whether this geotactic function of static sense organs is not more widely extended in the animal kingdom, especially as the existence of statocysts in many animals is not explained by their equilibrium function.

The equilibrium of many of these animals is maintained automatically by the distribution of masses and densities through the body, while other forms exhibit an almost indifferent equilibrium. Statocysts and similar organs

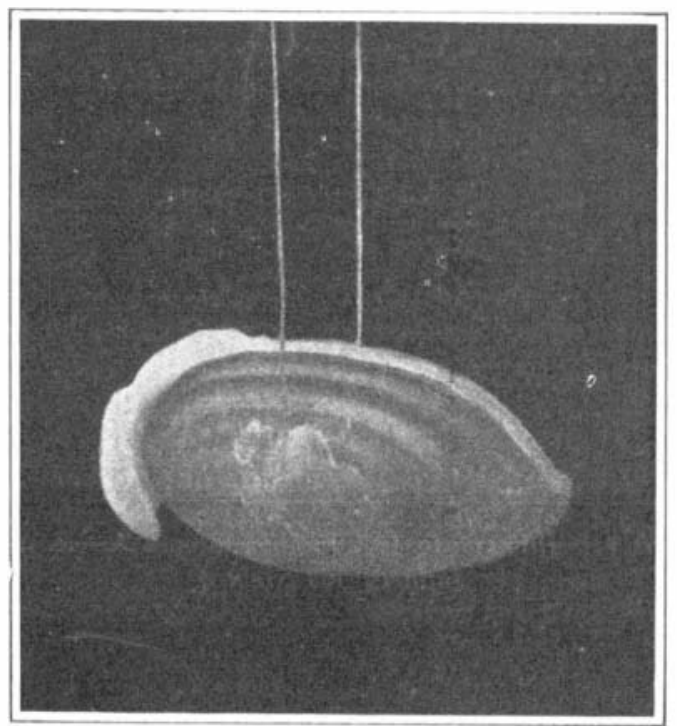

Fig. 5.-A suspended mussel protruding its foot toward the ground. an act as equilibrium organs only in animals whose equilibrium is naturally unstable. This is the case in running, flying and swimming animals, insofar as their equilibrium is not maintained automatically by their structure. Hence the statocysts found in numerous animals of stable or indifferent equilibrium must have another function. The well developed statocysts of animals that crawl and burrow in the earth have been especially that crawl

The equilibrium of the water scorpion, in water, is maintained automatically by the distribution of the reserve store of air beneath the wings. Here the negative geotactic function of the statocyst impels the animal, which seeks its food under water but is unable to rise directly when its air supply is exhausted, to reach the surface by climbing the stalk of a plant or crawling up the sloping bank. This is proved by the failure of the geotactic reaction when the statocyst is destroyed.

The burrowing movements of certain marine worms have lately been recognized as positive geotactic flightreflexes, originating in their statocysts and failing when these organs are removed. The pecten mussel possesses

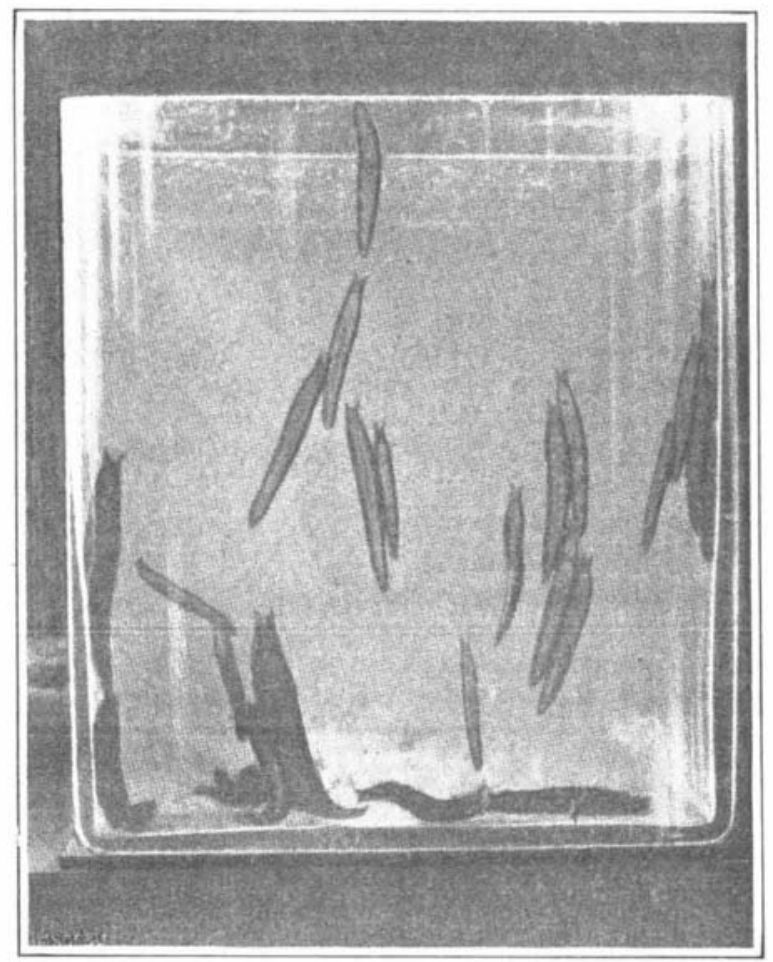

Fig. 4.-Submerged land slugs escaping from the water.

ymmetrically arranged statocysts, which maintain equilibrium in swimming and also, by reflex action, cause the animal to right itself when it is inverted,

Close study of our common land and fresh water mollusks reveals characteristic reactions which prove the possession of a strong power of orientation in a definite direction, determined by the conditions of life. When a snail (Arion or Limax) is placed on its back it turns its head into the normal crawling position, brings it into contact with the ground, and by crawling forward gradually brings the rest of the body into the erect position (Fig. 2). But this reflex turning movement does not occur if the foot of the inverted snail is in contact with any object along which the animal can (and does) crawl, without regard to its position in space. Hence the reflex is evoked by the freedom of the foot and inhibited by its contact with any object. It has been proved by experiment that this reflex is not caused by the ordinary sense of touch, or by the sense of taste, smell, or sight, for it persists when these senses are destroyed. When a snail is cut in two, however, the reflex persists, in weakened form, in that part which contains the statocysts and the nerve centers associated with them. A fairly long head segment of Limax promptly 
turns over when it is laid on its back, and a body, decapitated in such manner that it retains the brain and statocysts, exhibits the same reflex for weeks. The turning reflex, therefore, may be regarded as a function of the statocysts.

Definitely directed movements also play a great part in the life of terrestrial and aquatic mollusks. Aquatic pulmonate snails seek food under water but come to the purface for air, and some branchiate snails and mussels surface for air, and some branchiate snails and mussels
oscillate between greater and less depths for the same reasons, while land snails and slugs, when submerged in water, promptly make their escape if they can (Fig. 4). A terrarium can be rid of infesting snails very quickly by immersing it in water. Land snails placed on a seesaw under water always crawl upward, reversing their motion with each oscillation (Fig. 3). They exhibit the samenegative geotactic reaction in otherliquidsand gases. The reflex, therefore, is evoked by need of air. In Limax the reaction is not essentially altered by removing all sense organs except the statocysts, and the reflex persists in a severed segment that contains the statocyst and nerve ganglia. Hence the statocysts produce a negative geotactic reflex action in addition to the turning
reflex. The biological importance of this reflex of flight from impending asphyxiation need not be emphasized. Fresh water mussels exhibit positive geotactic reactions The essentially geotactic character of the movements of the thick muscular foot, by means of which the animg buries itself in the pond or river bed, can be proved by suspending a mussel by cords in the water of an aquarium. The protruded foot always turns to the bottom, even when the mussel is suspended in a position that make this action very difficult (Fig. 5). Here, as in burrowing marine animals, the reflex appears to be evoked by exposure and inhibited by the resistance which the foot encounters at a certain depth in the sand. The positive geotactic movements of these mussels are shown also by their burrows, always directed toward the deepest points in ponds that had been previously drained. Our general conclusion, therefore, is that static sense organs influence the motor mechanism in such a manner as to produce and to maintain, permanently or temporarily, in a state of rest or of locomotion, a definite bodily position, which may be one of unstable equilibrium. They may cause positive or negative geotactic movements, reflex righting of the inverted body and various other effects, but their presence in an animal always indicates a need of definite orientation determined by the definite conditions of existence. The faculty of orientation may be well developed, however, in an animal destitute of special static organs, for the functions of these may be performed by almost any other sense organs. This fact greatly increases the difficulty of determining the action of the statocysts by experiment, in species from which the statocysts cannot be removed, and in which no conclusions can be drawn from exceptional cases.

\section{The Wastefulness of Coke Ovens*}

\section{How They Can Advantageously Be Worked in Conjunction With Blast Furnaces}

\section{By Heinrich J. Freyn}

The evidence of statistical investigations made by E. W. Parker of the United States Geological Survey, is that only approximately 25 per cent of the total coke produced in this country in 1912 was made in by-product coke ovens, whereas 75 per cent was produced in beehive ovens. This entailed the enormous loss of over $\$ 80,000$, 000 in non-recovered by-products, such as gas, tar and ammonia, without considering the substantial loss due to the non-recovery of benzol from the coal.

BLAST Furnace as a slagging gas Producer.

By taking advantage of the recent innovation of $\mathrm{H}$. A. Brassert, blast furnaces are now able to insure fulfillment of a contract for the delivery of a specified uniform amount of power in times of business depression as well as activity. Brassert virtually transforms a non-active blast furnace into a huge gas producer, and gasifies in it small coke, raw coal, and coke breeze, on the principle of a slagging type of producer, using open-hearth slag as flux. This has been very successfully demonstrated at South Chi ment that curtailment of pig iron and coke production in times of business depression militates against maintaining, say, a gas-driven electric power plant.

In order to show what can be accomplished in the practical utilization of the surplus gases of a blast furnace and coke-oven plant of modern size, the following calculations are made:

Two isolated blast furnaces, of $\mathbf{3 5 0}$ and $\mathbf{4 5 0}$ tons daily capacity each, are installed near a large city, together with a coke-oven plant of just sufficient size to furnish the necessary coke for these blast furnaces. Coking coals of proper quality for making good blast-furnace coke can be delivered for $\$ 3$ per long ton f.o.b. the furnace.plant. The by-product coke is charged to the blast furnaces at $\$ 4.25$ per net ton, which price is about $\$ 1.25$ below the cost of standard beehive coke delivered in that locality. Coke-oven gas of a heating value of 550 B.t.u. per cubic foot, but not subject to minimum candle-power specifoot, but not subject to minimum candle-power speci-
fications, can be used in the city for domestic purposes and would bring a price of 12 cents per 1,000 cubic feet. The prevailing cost of electric power is 1.2 cents per kilowatt-hour, distributed. With a practically unlimited power market, the total surplus from the blast furnace and coke-oven gases of this plant can be absorbed by the established electric power company, which operates steam turbine power stations of approximately 300,000,000 kilowatt-hours total output per year generated at a yearly use factor of about 38 per cent.

With such favorable local conditions, the total quantity of coke-oven gas can be used for domestic or power purposes, or both. To realize this, gas from some outside source must be used for under-firing at the coke ovens. Blast-furnace gas should not be used for this purpose in this instance, since. this ideal gas-engine fuel can much more profitably be utilized for the production of electric power. Producer gas made from small coke and coke breeze in revolving grate or slagging type gas producers would answer splendidly and should be used if sufficient quantities of these fuels are available. As a general rule, however, the amount of coke breeze does not exceed 7 per cent. to 8 per cent. of the total coke made, and this quantity is not sufficient to produce the necessary gas for under-fining. In this discussion, it was assumed that a mixture of raw coal and coke breeze is gasified in some type of mechanically-stirred gas producer equipped with apparatus for the recovery of by-products. This pro-

*Extracts from a paper read at the New York meeting of the
American Institute of Mining Engineers, February 18th, 1914, and published in The Iron Age. ducer plant would be in operation at practically full output at all times, making this method of providing fo under-firing very cheap and attractive. The question whether the total quantity of coke-oven gas produced should be marketed for community. use, or only its rich portion, while the lean portion is used for power purpose in the natural state, or in admixture with blast-furnace gas, can be properly answered only when the quality of the coking coals is known and when the value of the coke oven gas is correctly appraised.

POSITION OF THE COKE-OVEN GAS ENGINE.

The blast-furnace gas engine has to-day attained a very high standard, as can readily be seen by the truly remarkable results achieved with the world's largest gasengine plant at Gary; but the coke-oven gas engine, although mechanically equivalent to the blast-furnace ga engine, has to deal with a fuel of entirely different character. The large percentage of hydrogen in coke-oven gas causes an extremely rapid flame propagation, so that the time of combustion of a mixture of coke-oven gas and air is considerably shorter, and this combustion much more of an explosive character, than is the case with blast-furnace gas. The compression in coke-oven gas engines must, on account of these characteristic qualitie of the fuel, be kept considerably lower than is customar and appropriate for blast-furnace gas engines. Costly experience has taught European gas-engine manufacturers to reduce the compression pressure in coke-oven gas engines to 110 , and even to 85 pounds per square inch, depending somewhat on the percentage of hydrogen in the gas.

Owing to the snappy action of the gas, coke-oven gas engines are at times quite susceptible to back-firing an premature explosions. Effective cooling of gas cylinders, pistons, piston rods, etc., becomes, therefore, a very important matter on account of the intense heating of thes parts. The absolute quantities of coke-oven gas consumed during one working cycle are comparatively small even at full load, and perfect regulation of coke-oven gas engines is, therefore, not so easily accomplished as that of blast-furnace gas engines. Serious difficultie were encountered in the earlier days because it was found quite impossible to maintain satisfactory parallel opera tion, especially at fractional loads, on coke-oven gas engine generators feeding. into the same system. Ignorance on the designer's part was very largely responsible for these difficulties because gas ports and gas-valve area were made far too large, and entirely out of proportio to the size of the air ports, since no attention was paid to the low specific gravity of coke-oven gas. Much large quantities of gas than actually required at any specific load were thus caused to enter the gas cylinders, and these earlier engines nearly always operated on excessively rich mixtures. The obvious result was, after burning, destruction of exhaust valves, piston rods, and cylinders, violent back-fires and vicious premature ex-
plosions, all of which caused extremely unsatisfactory plosions, all of whic

To-day, the coke-oven gas engine has reached such high state of perfection in Germany that it is second only to the blast-furnace gas engine in importance and serviceableness, with the qualification, however, that unit capacity and more particularly the rating must be conservative.

The latest coke-oven gas engines installed at Bonifacius colliery in Westphalia, are of the twin-tandem double-acting, four-cycle type having four gas cylinder $47 \frac{1}{2}$ inches in diameter, 51 inch stroke, and develop at 94 revolutions per minute about 5,000 b.h.p. Parallel operation is beyond eriticism, and the load factor of these engines is very high-from 90 to 100 per cent-since peak loads are taken up by the blast-furnace gas-engine plant and the steam turbines. These engines were built two years ago and are probably the largest coke-oven gas engines in the world. The compression pressure is only 85 pounds and the maximum explosion pressure does not exceed 250 pounds per square inch. Each cylinder end is provided with three igniters. The gas consumption as measured by means of a large gas holder was found to be 12,000 B.t.u. per kilowatt-hour at 90 to 100 per cent load. The over-all mechanical efficiency, including generator, is 82.3 per cent at that load.

The overwhelming majority of gas-engine manufacturers in this country restrict the capacity of coke-oven gas engines to about 700 or 750 b.h.p. per double-acting cylinder at present. This prudent and conservative policy on the part of American gas-engine builders shows excellent judgment. The coke-producing industries should encourage this spirit and assist the manufacturers by installing coke-oven gas engines to about 700 or 850 b.h.p. per double-acting eylinder.

It should be remembered that the presence of sulphur in coke-oven gas in the form of sulphuretted hydrogen and carbon bisulphide was the cause of very serious troubles before it was learned how to combat its influence. The slightest water leak in the gas eylinders from defective pistons or water-cooled. exhaust valves resulted in serious corrosion of all finished parts, and particularly of piston rings, piston rods, and metallic packing. This cor osion was caused by sulphuric acid formed by the combination with oxygen and water of sulphur dioxide, resulting from the combustion of sulphur in the gas. Instead of striking at the root of the evil by proper sulphur purification, and by prevention of water leaks, attempt was made to cure the trouble by resorting to building materials which would not be attacked by sulphuric acid.

Considerable progress has been made in recent years in designing sulphur cleaning plants which eliminate nearly all of the sulphuretted hydrogen, although no practical means has so far been discovered to separate carbon bisulphide from the gas. Gas-engine manufacturers in Europe are, however, willing to guaranteo satisfactory and continuous operation of gas engines supplied with purified coke-oven gas containing as much as 1.25 grammes of sulphur compounds in one cubic foot.

Naphthalene which is deposited by the gas, particularly in cold weather, easily obstructs pipe lines and valves. This also has been the cause of much annoyance. If benzol is recovered from the gas, no trouble from naphthalene deposits can occur, since it is absolutely necessary for efficient benzol recovery to extract the naphthalene from the gas. In plants where benzol is not recovered, it happens not infrequently that the gas pipes, etc., have to be steamed out from time to time in order to dissolve the naphthalene, which otherwise accumulates in the piping and on the valves, until the output of the power plant is noticeably reduced. Incidentally benzol recovery, in connection with by-product coke-oven plants, improves gas-engine operation owing to the elimination of certain hydrocarbons, and because the heating value of the gas is reduced about 5 per cent. Coke-oven gas used for power purposes, or as fuel in a steel plant, does not require any illuminating properties; the recovery of the benzol from the gas for sale offers very attractive financial possibilities, and yields an exceptionally handsome profit on the investment.

A straight-forward acknowledgment of the salient 